\title{
ANALISA TROUBLE DIFFERENTIAL RELAY TERHADAP TRIP CB ( CIRCUIT BREAKER ) 150 KV TRANSFORMATOR 30 MVA PLTGU PANARAN
}

\author{
Muhammad Irsyam \\ Program Studi Teknik Elektro, Fakultas Teknik, Universitas Riau Kepulauan
}

Sistem proteksi merupakan kesatuan yang tidak dapat dipisahkan dalam ketenagalistrikan. Sistem proteksi yang handal akan menjaga sistem kelistrikan serta menjaga alat dari kerusakan yang lebih besar akibat gangguan dalam ( internal ) dan gangguan luar ( external ). Salah satu sistem proteksi adalah relai differential transformator. Relai differential merupakan proteksi utama sebuah transformator ( main protection ). Relai differential bekerja sangat selektip dan cepat tanpa waktu jeda ( time delay ). Relai differential bekerja pada saat ada gangguan dalam area pengamanannya yang dibatasi oleh transformator arus dan tidak boleh bekerja pada saat ada gangguan luar. Oleh karena itu pemasangan relai differential harus benar dan sesuai dengan standar ketenagalistrikan.

Dalam kehidupan serba modern ini serta penuh dengan rekayasa teknologi, pemenuhan akan kebutuhan energi listrik yang digunakan untuk menjalankan peralatan yang diciptakan untuk mempermudah kehidupan manusia mutlak diperlukan. Peralatan itu baik yang digunakan dalam rumah tangga, peralatan perkantoran sampai peralatan yang digunakan dalam dunia industri.

Tegangan yang dikirim dari Pembangkit Panaran adalah tegangan menengah yaitu $11 \mathrm{kV}$, selanjutnya tegangan menengah itu dinaikkan ke tegangan tinggi $150 \mathrm{kV}$ melalui transformator step-up yang berada di GI Panaran. Untuk menjaga kehandalan dan keawetan Tranformator pembangkit dipasanglah beberapa rele pengaman yaitu : relai over current, relai ground fault, relai differential, relai bucholz, relai thermal.

Kendala dalam proses penyaluran energi listrik cukup banyak baik dibagian hulu maupun dibagian hilir. Untuk dibagian hulu yaitu di pembangkit listrik bisa disebabkan oleh mesin pembangkit, transformator pembangkit, bahan bakar dan lain-lainnya. Salah satunya terjadi gangguan pada transformator 30 MVA PLTGU terjadi TRIP dengan indikasi relai differensial trip yang bersamaan dengan gangguan yang terjadi pada line transmisi $150 \mathrm{kV}$ oleh petir pada line 2 Batu Besar - Muka Kuning dan line 2 Baloi - Sengkuang. Seharusnya transformator PLTGU Panaran tidak terjadi trip karena gangguan yang terjadi pada line transmisi, bukan pada area dari transformator itu sendiri, sehingga seharusnya relai diferensial tidak bekerja.

\section{Transformator}

Transformator adalah suatu peralatan listrik yang termasuk dalam klasifikasi mesin listrik statis dan berfungsi untuk menyalurkan tenaga/daya listrik dari tegangan tinggi ke tegangan rendah atau sebaliknya, dengan frekuensi sama, melalui suatu gandengan magnet dan berdasarkan prinsip induksi elektromagnet ( hukum Faraday ).

Transformator terdiri dari beberapa bagian yang saling terkait dan membentuk peralatan listrik yang berfungsi menyalurkan daya serta sebagai penaik atau penurun tegangan.

Transformator terdiri atas tiga bagian yaitu :

1. Bagian utama Transformator 
2. Peralatan bantu

3. Peralatan proteksi

\section{Sistem Proteksi}

Relai proteksi adalah susunan peralatan yang direncanakan untuk dapat mendeteksi adanya kondisi abnormal pada peralatan atau bagian sistem tenaga listrik dan segera secara otomatis membuka pemutus tenaga ( PMT ), untuk memisahkan peralatan atau bagian dari sistem tenaga listrik yang terganggu dan memberi isyarat berupa lampu dan alarm. Bentuk dari hubungan dari relai proteksi tampak seperti gambar.

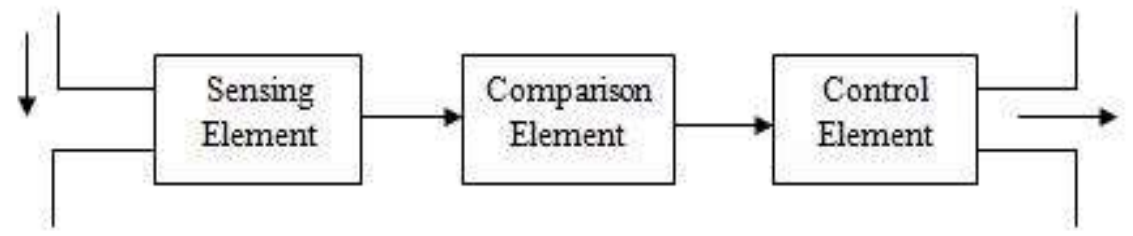

Gambar1. Elemen dasar relai proteksi

1. Elemen sensor ( sensing element) merupakan elemen yang berfungsi untuk memberi tanggapan / reaksi terhadap adanya perubahan-perubahan besaran seperti tegangan, arus, frekuensi, suhu dan lain-lain yang menandakan adanya gangguan.

2. Elemen pembanding ( comparison element) merupakan suatu elemen yang berfungsi untuk membandingkan besaran listrik yang diukur atau yang terdeteksi terhadap besaran yang ditentukan.

3. Elemen pemutus ( control element) merupakan suatu elemen yang berfungsi untuk mengambil keputusan dalam mengirimkan sinyal kepada pemutus tenaga ( PMT ) baik secara seketika maupun dengan perlambatan waktu ( waktu tunda ).

\section{Transformator Arus}

Transformator Arus (Current Transformator) yaitu peralatan yang digunakan untuk melakukan pengukuran besaran arus pada intalasi tenaga listrik disisi primer (TET, TT dan TM) yang berskala besar dengan melakukan transformasi dari besaran arus yang besar menjadi besaran arus yang kecil secara akurat dan teliti untuk keperluan pengukuran dan proteksi.

Pemilihan rasio transformator arus harus sesuai dengan persamaan dibawah ini.

Dimana :

$$
\text { In }=\frac{\mathrm{S}}{\mathrm{kV} \times \sqrt{3}}
$$

In $=$ arus nominal $(\mathrm{A})$

$\mathrm{S}$ = daya yang tersalur ( MVA )

\section{Relai Differential}

Proteksi differential merupakan salah satu pelindung utama pada transformator daya bila terjadi short circuit atau terjadi hubung singkat antar fasa di internal peralatan ( daerah yang diproteksi). Prinsip dari relai differential adalah sesuai dengan hukum arus kirchoff yaitu :

"Jumlah aljabar dari arus yang menuju / masuk dengan arus yang meninggalkan / keluar pada titik sambungan / cabang sama dengan nol. 


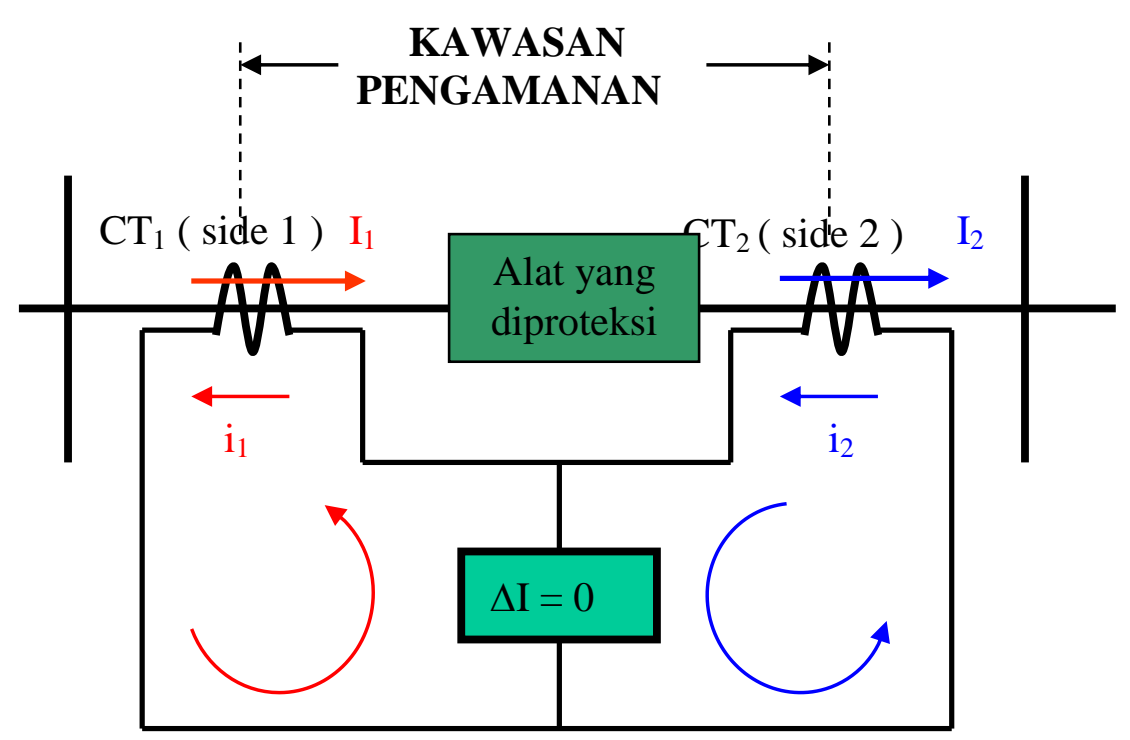

Gambar 2. Gambar relai differential

Prinsip kerja relai proteksi differential adalah membandingkan dua vektor arus atau lebih yang masuk ke relai ( lihat gambar 2.2), apa bila pada sisi primer transformator arus $\left(\mathrm{CT}_{1}\right)$ dialiri arus $\mathrm{I}_{1}$, maka pada sisi primer transformator arus $\left(\mathrm{CT}_{2}\right.$ ) akan dialiri arus $\mathrm{I}_{2}$ ( dalam pembahasan nanti untuk CT2 sama dengan side 2 yang nilainya hasil dari M2-M3 ), pada saat yang sama sisi sekunder kedua transformator arus ( side 1 dan side 2 ), akan mengalir arus $i_{1}$ dan $\mathrm{i}_{2}$ yang besarnya tergantung dari rasio yang terpasang, jika besarnya $\mathrm{i}_{1}=\mathrm{i}_{2}$ maka relai tidak bekerja, karena tidak ada selisih arus $(\Delta \mathrm{i}=0)$, tetapi jika besarnya arus $\mathrm{i}_{1} \neq \mathrm{i}_{2}$ maka relai akan bekerja, karena adanya selisih arus $(\Delta \mathrm{i} \neq 0)$.

Selisih arus ini disebut arus differential. Arus inilah yang menjadi dasar bekerjanya relai diferensial. Jadi bisa disimpulkan :

$$
\begin{aligned}
& I_{\text {diferensial }}=I_{d}=\left|\overrightarrow{I_{P}}\right|+\left|\overrightarrow{I_{S}}\right| \\
& \text { Dimana : } \\
& \text { Id }=\text { Arus diferensial (A) } \\
& \text { Ip }=\text { Arus sisi masuk / primer ( A ) } \\
& \text { Is = Arus sisi keluar / sekunder ( A ) }
\end{aligned}
$$

\section{Karakteristik Relai Differential}

Karakteristik differential dibuat sejalan dengan unbalances current ( I $\mu$ ), untuk menghindari kesalahan kerja. Kesalahan kerja disebabkan karena CT ratio mismatch, pergeseran fasa akibat belitan transformator terhubung ( $\mathrm{Y})-(\Delta)$, perubahan tap tegangan ( OLTC), kesalahan akurasi CT, perbedaan kesalahan CT di daerah jenuh ( saturasi CT ), dan inrush current pada saat transformator energize dapat menimbulkan unbalances current ( $\mathrm{I} \mu$ ) yang bersifat transient. 


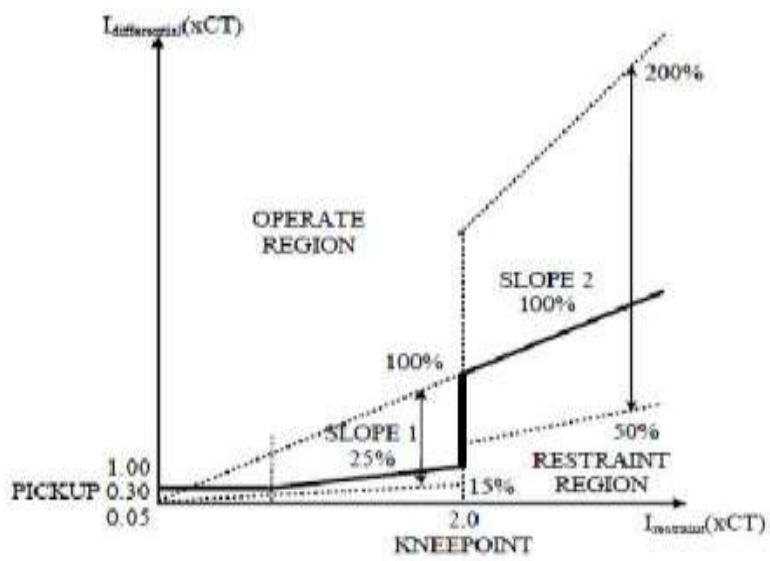

Gambar 3. Karakteristik presentase differential

Slope adalah karakteristik ( kecuraman / lengkungan ) yang didapat dari membagi antara komponen arus diffeential $\left(\mathrm{I}_{\mathrm{d}}\right)$ dengan arus penahan $\left(\mathrm{I}_{\mathrm{r}}\right)$.

Untuk $\mathrm{Ir}=\mathrm{I}$ restrain $=\frac{I 1+I 2}{2}$

Untuk besaran setting $\%$ Slope $=\frac{\mathrm{Id}}{\mathrm{Ir}} \times 100 \%$

\section{Pengumpulan Data Transformator}

Tabel1. Data Transformator

\begin{tabular}{|l|l|l|}
\hline NO & Deskripsi & Data \\
\hline 1 & Jumlah Fasa & 3 \\
\hline 2 & Jumlah lilitan / winding & 2 \\
\hline 3 & Rated frequency & $50 \mathrm{~Hz}$ \\
\hline 4 & Rated MVA & $25 / 30 \mathrm{MVA}$ \\
\hline 5 & $\mathrm{HV}($ High Volt $)$ & $150 \mathrm{kV}$ \\
\hline 6 & LV $($ Low Volt $)$ & $11 \mathrm{kV}$ \\
\hline 7 & Resistensi winding $\left(20^{\circ}\right)$ & \\
& - per fasa HV & $2,10301 \Omega$ \\
& - per fasa LV & $0,02676 \Omega$ \\
\hline 8 & Impedansi & $12 \%$ at 25 MVA \\
\hline
\end{tabular}

\subsection{Data Transformator Arus}

Tabel 2. Data CT ( current transformer)

\begin{tabular}{|l|l|l|l|l|l|}
\hline NO & Data & Primer & Sekunder & Ratio CT & Spesifikasi \\
\hline 1 & CT 1 ( M1 ) & 150 & 1 & $150: 1$ & 5P20, 30 VA \\
\hline 2 & CT 2 ( M2 ) & 2000 & 1 & $2000: 1$ & 5P20, 40 VA \\
\hline 3 & CT 3 ( M3 ) & 200 & 1 & $200: 1$ & 5P20, 40 VA \\
\hline
\end{tabular}


Nilai dari ratio $\mathrm{CT}$ yang tertera pada tabel didapat dari perhitungan dengan mengggunakan persamaan :

$$
\text { I nominal }=\frac{\mathrm{S}}{\mathrm{kV} \times \sqrt{3}}
$$

Untuk perhitungannya seperti di bawah ini :

Untuk sisi CT 1 ( M1 )/ high volt ( HV ) :

$$
\text { In sisi } 150 \mathrm{kV}=\frac{30 \mathrm{MVA}}{150 \times \sqrt{3}}=\frac{30.000}{259,807}=115,47 \mathrm{~A}
$$

Untuk sisi CT 2 ( M2 ) / low volt ( LV ):

$$
\text { In sisi } 11 \mathrm{kV}=\frac{30 \mathrm{MVA}}{11 \times \sqrt{3}}=\frac{30.000}{19,052}=1574,64 \mathrm{~A}
$$

Untuk sisi CT 3 ( M3 ) / auxilary:

$$
\text { In sisi } 11 \mathrm{kV}(\text { auxilary })=\frac{2,5 \mathrm{MVA}}{11 \mathrm{x} \sqrt{3}}=\frac{2500}{19,052}=131,22 \mathrm{~A}
$$

Pemilihan CT ynag digunakan disesuaikan dengan yang ada dipasaran yang memiliki nilai mendekati arus ratingnya.

\section{Data Arus Differential dan Setting Relai Differential}

Tabel 3. Arus differential dan arus restrain pada saat gangguan

\begin{tabular}{|l|l|l|}
\hline Fasa & I Diff & I Rest \\
\hline $\mathrm{R}$ & $0,09 \mathrm{I} / \mathrm{InO}$ & $0,34 \mathrm{I} / \mathrm{InO}$ \\
\hline $\mathrm{S}$ & $0,33 \mathrm{I} / \mathrm{InO}$ & $0,41 \mathrm{I} / \mathrm{InO}$ \\
\hline $\mathrm{T}$ & $0,13 \mathrm{I} / \mathrm{InO}$ & $0,51 \mathrm{I} / \mathrm{InO}$ \\
\hline
\end{tabular}

\section{Perhitungan Setting Relai Differential}

Sebelum menganalisa gangguan yang terjadi pada transformator pembangkit sebaiknya kita mencari dulu nilai dari setting relai differential yang telah ditetapkan dengan persamaan: Sisi High voltage :

Iflp ( arus full load di sisi primer ) $150 \mathrm{kV}=\frac{30 \mathrm{MVA}}{\sqrt{3} \times 150 \mathrm{kV}}=\frac{30000}{259,8}$

Iflp sisi $150 \mathrm{kV}=115,47 \mathrm{~A}$

Ifls ( arus full load sisi sekunder ) $150 \mathrm{kV}=115,47 \times \frac{1}{150}$

Ifls sisi $150 \mathrm{kV}=0,7698 \mathrm{~A}$

Sisi low voltage :

Iflp ( arus full load di sisi primer ) $11 \mathrm{kV}=\frac{30 \mathrm{MVA}}{\sqrt{3} \times 11 \mathrm{kV}}=\frac{30000}{19,052}$

Iflp sisi $11 \mathrm{kV}=1574,64 \mathrm{~A}$

Ifls ( arus full load sisi sekunder ) $11 \mathrm{kV}=1574,64 \times \frac{1}{2000}$

Ifls sisi $150 \mathrm{kV}=0,7873 \mathrm{~A}$

Arus di relai differential pada saat beban penuh ( persamaan 2.13 ) :

I op $=\mid$ Ifls sisi $150 \mathrm{kV}-$ Ifls sisi $11 \mathrm{kV} \mid$

I op $=|0,7698-0,7873|$

I op $=|-0,0175|=0,0175 \mathrm{~A}$ 
I restrain $=\mid$ Ifls sisi $150 \mathrm{kV}|+|$ Ifls sisi $11 \mathrm{kV} \mid$

I restrain $=|0,7698|+|0,7873|$

I restrain $=|1,5571|=1,5571 \mathrm{~A}$

Pada kondisi normal arus full load di relai differential adalah :

$\frac{0,0175}{1,5571} \times 100=1,1239 \%$

Setting relai differential :

Min. setting $=$ Error tap tranformator $(\%)+$ mismatching $(\%)+$ error CT $(\%)+$ toleransi

$$
\begin{aligned}
& =\left(\frac{2 \times 2,5}{150} \times 100 \%\right)+1,1239 \%+5 \%+5 \% \\
& =3,333 \%+1,1239 \%+5 \%+5 \% \\
& =14,45 \%
\end{aligned}
$$

Untuk setting relai differential yang digunakan $30 \%$ atau $0,3 \mathrm{I} / \mathrm{In} \mathrm{Tr}$.

Untuk menghitung slope minimum setting yaitu :

Arus differential pada sisi high volt ( $150 \mathrm{kV})$

$$
\text { I op }=0,30 \times \frac{150}{1}
$$

I op $=45$ A pada sisi $150 \mathrm{kV}$

I restrain $=1,5571 \times \frac{150}{1}$

I restrain $=233,57$ pada sisi $150 \mathrm{kV}$

Arus differential pada sisi low volt ( $11 \mathrm{kV})$

$$
\begin{aligned}
& \text { I op }=0,30 \times \frac{2000}{1} \\
& \text { I op }=600 \text { A pada sisi } 11 \mathrm{kV} \\
& \text { I restrain }=1,5571 \times \frac{2000}{1} \\
& \text { I restrain }=3114,2 \text { pada sisi } 11 \mathrm{kV}
\end{aligned}
$$

Setting slope 1 minimum :

Slope $(\%)=\frac{I d}{\text { Irestrain }} \times 100 \%$

$$
\begin{aligned}
& =\frac{45}{233,57} \times 100 \% \\
& =19,266 \% \text { ( standar dari PLN } 20 \% \text { sampai } 30 \%)
\end{aligned}
$$

Setting yang dipakai relai Siprotec Siemens 7UT613 saat ini $30 \%$.

Setting slope 2 minimum :

$$
\begin{aligned}
& =\left(\frac{45}{233,57}\right) 2 \times 100 \% \\
& =38,53 \% \quad(\text { standar dari PLN } 40 \% \text { sampai } 60 \%)
\end{aligned}
$$

Setting yang dipakai relai Siprotec Siemens 7UT613 saat ini $50 \%$.

\section{Analisa Gangguan Saat Relai Differential Bekerja ( Trouble Shooting )}

1. Analisa pada Transformator

Hasil perhitungan besaran arus differential secara teoritis saat relai bekerja :

Sisi high voltage ( M1):

Fasa R : Ip sisi $150 \mathrm{kV}=18,9 \mathrm{~A}$

$$
\text { Is sisi } 150 \mathrm{kV}=18,9 \times \frac{1}{150}=0,126 \mathrm{~A}
$$


Fasa S : Ip sisi $150 \mathrm{kV}=18,2 \mathrm{~A}$

Is sisi $150 \mathrm{kV}=18,2 \times \frac{1}{150}=0,121 \mathrm{~A}$

Fasa T : Ip sisi $150 \mathrm{kV}=20,5 \mathrm{~A}$

Is sisi $150 \mathrm{kV}=20,5 \mathrm{x} \frac{1}{150}=0,136 \mathrm{~A}$

Sisi low voltage ( $\mathrm{M} 2$ ):

Fasa R : Ip sisi $11 \mathrm{kV}=0,89 \mathrm{~A}$

Is sisi $11 \mathrm{kV}=0,89 \mathrm{x} \frac{1}{2000}=0,0005 \mathrm{~A}$

Fasa $\mathrm{S}$ : $\quad$ Ip sisi $11 \mathrm{kV}=1,2 \mathrm{~A}$

Is sisi $11 \mathrm{kV}=1,2 \times \frac{1}{2000}=0,0006 \mathrm{~A}$

Fasa T : Ip sisi $11 \mathrm{kV}=1,92 \mathrm{~A}$

Is sisi $11 \mathrm{kV}=1,92 \times \frac{1}{2000}=0,0009 \mathrm{~A}$

Sisi low voltage ( M3) :

Fasa R : Ip sisi $11 \mathrm{kV}=274 \mathrm{~A}$

Is sisi $11 \mathrm{kV}=274 \mathrm{x} \frac{1}{200}=1.37 \mathrm{~A}$

Fasa S : Ip sisi $11 \mathrm{kV}=242 \mathrm{~A}$

Is sisi $11 \mathrm{kV}=242 \times \frac{1}{200}=1,21 \mathrm{~A}$

Fasa T: Ip sisi $11 \mathrm{kV}=268 \mathrm{~A}$

Is sisi $11 \mathrm{kV}=268 \times \frac{1}{200}=1,34 \mathrm{~A}$

Arus di side 1:

I nominal $=\frac{25 M V A}{\sqrt{3} \times 150}=\frac{25000}{259,8}=96,23 \mathrm{~A}$

Fasa R : I sisi $150 \mathrm{kV}=18,9 \mathrm{~A}$

I sisi $150 \mathrm{kV}=18,9 \times \frac{1}{96,23}=0,196 \mathrm{~A}$

Fasa $\mathrm{S}$ : I sisi $150 \mathrm{kV}=18,2 \mathrm{~A}$

$$
\text { I sisi } 150 \mathrm{kV}=18,2 \times \frac{1}{96,23}=0,189 \mathrm{~A}
$$

Fasa T : I sisi $150 \mathrm{kV}=20,5 \mathrm{~A}$

$$
\text { I sisi } 150 \mathrm{kV}=20,5 \times \frac{1}{96,23}=0,212 \mathrm{~A}
$$

Arus di side 2 :

I nominal $=\frac{25 M V A}{\sqrt{3} \times 11}=\frac{25000}{19,052}=1312,19 \mathrm{~A}$

Fasa $\mathrm{R}$ : I sisi $11 \mathrm{kV}=(274-0,89)=273,11 \mathrm{~A}$

$$
\text { I sisi } 11 \mathrm{kV}=273,11 \mathrm{x} \frac{1}{1312,19}=0,208 \mathrm{~A}
$$

Fasa S : I sisi $11 \mathrm{kV}=(242-1,2)=240,8 \mathrm{~A}$

$$
\text { I sisi } 11 \mathrm{kV}=240,8 \times \frac{1}{1312,19}=0,184 \mathrm{~A}
$$

Fasa T : I sisi $11 \mathrm{kV}=(268-1,92)=266,08 \mathrm{~A}$

$$
\text { I sisi } 11 \mathrm{kV}=266,08 \times \frac{1}{1312,19}=0,203 \mathrm{~A}
$$

Jadi arus differential nya ( I diff ) :

$\mathrm{I}$ diff $=\mid$ side 1 - side $2 \mid$

I diff $($ fasa R $)=|0,196-0,208|=0,012$

I diff $($ fasa $\mathrm{S})=|0,189-0,184|=0,004$ 
I diff ( fasa $\mathrm{T})=|0,212-0,203|=0,009$

Untuk arus restrain ( $I$ rest ):

I rest $=\mid$ side $1+$ side $2 \mid$

I rest $($ fasa $\mathrm{R})=|0,196+0,208|=0,404$

I rest ( fasa $S)=|0,189+0,184|=0,373$

I rest $($ fasa $T)=|0,212+0,203|=0,415$

Pada saat gangguan arus differential terbesar pada fasa R.

$$
\begin{aligned}
& \frac{0,012}{0,404} \times 100 \%=2,97 \% \\
& 2,97 \%<30 \% \text { maka relai differential tidak bekerja. }
\end{aligned}
$$

Dari perhitungan secara teoritis nilai arus differential masih dibawah nilai setting dari relai differential, berarti transformator tidak mengalami gangguan dan relai seharusnya tidak bekerja. Tetapi kenyataannya relai differential bekerja differential bekerja dengan arus differential fasa $\mathrm{S}$ melebihi nilai setting. Dari perhitungan dan dari hasil download pada relai differential terdapat perbedaan yang sangat besar.

2 Analisa Pada Transformator Arus ( CT )

Transformator arus yang dipakai :

CT $1($ M1 $)=150: 1$ spesifikasi 5P20, $30 \mathrm{VA}$

CT $2($ M2 $)=2000: 1$ spesifikasi 5P20, $40 \mathrm{VA}$

CT $3($ M2 ) = $200: 1$ spesifikasi 5P20, 40 VA

Dari data dapat diketahui pada CT 1 dan CT 2 arus yang melewati relatif kecil dan berarti masih jauh dari kejenuhan transformator arus, sedangkan pada CT3 ( M3 ) dapat dilihat bahwa arus yang melewati transformator arus melebihi dari arus pengenalnya tetapi masih dalam batas aman dari kejenuhan CT nya yang mencapai beberapa kali dari arus pengenalnya, dan ini berarti transformator arus tidak mengalami masalah.

\section{Analisa Pada Relai Differential}

Pemasangan relai differential harus benar dan sesuai dengan standarnya sehingga tidak salah kerja. Kesalahan kerja dapat terjadi oleh beberapa faktor seperti penyetelan relai, polaritas yang terbalik, kejenuhan dari CT yang digunakan pada proteksi ini.

Untuk memecahkan dari persoalan di atas dengan cara melihat besaran arus saat transformator beroperasi normal. Untuk lebih mudah dipahami akan dilihat pada gambar1. Pada gambar terlihat arah aliran arus dan letak dari CT yang digunakan. 


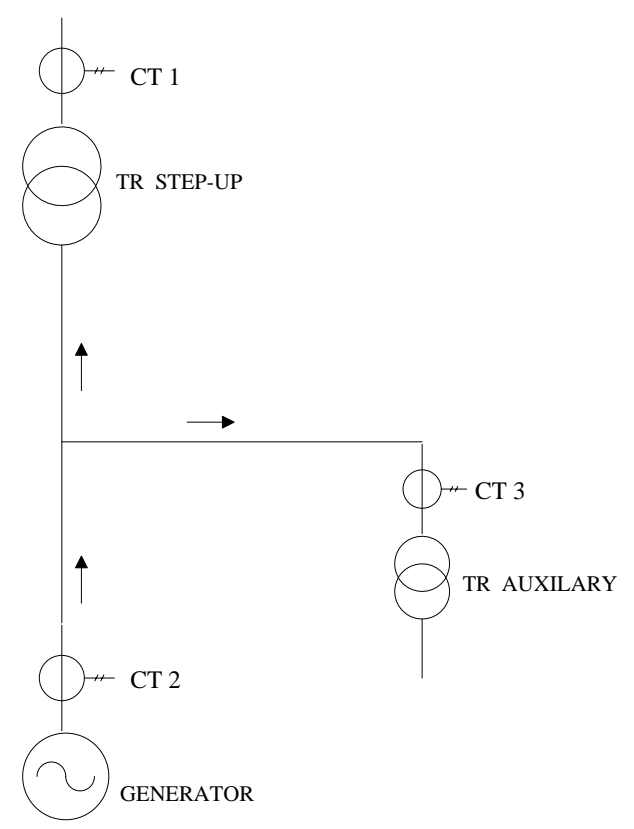

Gambar 1. Arah arus dan letak current transformator ( CT )

Untuk data arus transformator pada saat transformator beroperasi normal adalah sebagai berikut :

$$
\begin{array}{cccc}
\mathrm{CT} 1(\mathrm{M} 1)): \mathrm{R}=34,9 \text { A CT } 2(\mathrm{M} 2): \mathrm{R}=0,55 \mathrm{kA} \mathrm{CT} 3(\mathrm{M} 3) & \mathrm{R}=0,06 \mathrm{kA} \\
\mathrm{S}=35,6 \text { A } & \mathrm{S}=0,54 \mathrm{kA} & \mathrm{S}=0,06 \mathrm{kA} \\
\mathrm{T}=69,2 \mathrm{~A} & \mathrm{~T}=0,55 \mathrm{kA} & \mathrm{T}=0,06 \mathrm{kA}
\end{array}
$$

CT 2 ( M2 ) adalah sumber arus ( generator), untuk CT 1 ( M1 ) tranformator sisi tegangan tinggi dan untuk CT 3 ( M3 ) adalah auxilary atau PS

( pemakaian sendiri ). Sesuai dengan hukum kirchoff yaitu jumlah arus yang masuk ketitik percabangan sama dengan jumlah arus yang keluar dari titik percabangan.

Dari hasil penelitian dari relai differential dengan untuk side 1( sisi tegangan tinggi ) dan side 2 ( sisi tegangan rendah ) pada saat beroperasi normal sebagai berikut :

$$
\begin{array}{rrr}
\text { Side } 1: \mathrm{R} & =35,3 \mathrm{~A} & \text { Side } 2: \mathrm{R}=490 \mathrm{~A} \\
\mathrm{~S} & =35,6 \mathrm{~A} & \mathrm{~S}=610 \mathrm{~A} \\
\mathrm{~T} & =36,3 \mathrm{~A} & \mathrm{~T}=490 \mathrm{~A}
\end{array}
$$

Dari data diatas terlihat untuk fasa $\mathrm{R}$ dan $\mathrm{T}$ nilainya sama yaitu 490 A dan untuk fasa $\mathrm{S}$ nilainya jauh lebih tinggi yaitu $610 \mathrm{~A}$. Dengan teoritis untuk side 2 didapat dari :

$$
\begin{aligned}
& \mathrm{R}=\mathrm{M} 2-\mathrm{M} 3=0,55 \mathrm{kA}-0,06 \mathrm{kA}=0,49 \mathrm{kA} \\
& \mathrm{S}=\mathrm{M} 2-\mathrm{M} 3=0,54 \mathrm{kA}-0,06 \mathrm{kA}=0,48 \mathrm{kA} \\
& \mathrm{T}=\mathrm{M} 2-\mathrm{M} 3=0,55 \mathrm{kA}-0,06 \mathrm{kA}=0,49 \mathrm{kA}
\end{aligned}
$$

Dari perhitungan di atas didapat nilai untuk fasa $\mathrm{S}$ adalah $0,48 \mathrm{kA}=480 \mathrm{~A}$. Dari data relai differential fasa $\mathrm{S}$ sebesar $610 \mathrm{~A}$ itu sama dengan :

Fasa $\mathrm{S}$ side $2=\mathrm{M} 2+\mathrm{M} 3$

$$
=540 \mathrm{~A}+60 \mathrm{~A}=600 \mathrm{~A}
$$

ada sedikit perbedaan dengan data relai yaitu $610 \mathrm{~A}$. 
Untuk arus differential dan arus restrain dari pembacaan relai yang telah di download seperti berikut :
I diff : $\mathrm{R}=0,02 \mathrm{I} / \mathrm{InO}$
I rest : $\mathrm{R}=0,83 \mathrm{I} / \mathrm{InO}$
$\mathrm{S}=0,09 \mathrm{I} / \mathrm{InO}$
$\mathrm{S}=0,85 \mathrm{I} / \mathrm{InO}$
$\mathrm{T}=0,03 \mathrm{I} / \mathrm{InO}$
$\mathrm{T}=0,86 \mathrm{I} / \mathrm{No}$

Dari data di atas terlihat nilai differential untuk fasa $\mathrm{S}$ jauh lebih tinggi dari fasa $\mathrm{R}$ dan $\mathrm{T}$, ini menunjukkan ada kesalahan pada relai differential.

\section{Kesimpulan}

Setelah melakukan analisa dengan membandingkan hasil dari perhitungan dengan hasil dari relai diferensial transformator ( $87 \mathrm{~T}$ ) saat relai bekerja, maka dapat mengambil kesimpulan bahwa yang menyebabkan relai differensial bekerja adalah :

1. Polaritas terbalik pada transformator arus pada auxilary pada fasa $\mathrm{S}$ sehingga memberi input yang salah pada relai diferensial pada saat ada gangguan eksternal. Untuk mengatasinya adalah membalik polaritas dari transformator arus pada fasa $S$ yang terpasang pada auxilary.

\section{Saran}

Untuk menigkatkan kehandalan dan mutu ketenagalistrikan khususnya pada PLN Batam, penulis memberikan saran sebagai berikut :

1. Pada saat komisioning ( pengetesan ) pada relai proteksi transformator seharusnya dilakukan secara benar dan menyeluruh, sehingga apabila ada kesalahan pemasangan atau tidak berfungsinya suatu peralatan sesuai fungsinya dapat ditemukan sedini mugkin sebelum masuk ke sistem.

2. Pengawasan pada kontraktor pada saat pembangunan sistem ketenagalistrikan harus baik dan benar.

\section{DAFTAR PUSTAKA}

1. Anonim. 2009. Draft Pedoman O\&M Current Transformer, PLN Persero.

2. Ariatman, 2012. Materi Hukum Kirchoff

3. PLN ( Persero ), 2006. Modul Proteksi, UDIKLAT Semarang

4. Liem Ek Biem \& Dita Helna. Studi Penyetelan Relai Diferensial Pada Transformator PT Chevron Pasific Indonesia, JETri, Volume 6, Nomer 2, Februari 2007, Halaman 41 - 68, ISSN 1412 - 0372.

5. Mukti K, Harrij. Aplikasi Teknologi Simulasi Relai Diferensial Dan Rele Bucholz Pada Sistem Pengaman Transformator 3 Phasa, Jurnal ELTEK, Volume 05 Nomor 01, April 2007 ISSN1693 - 4024. 
6. Wahyudi, Iwan. 2010. Analisa Proteksi Differential Relay Generator Menggunakan GE 489 Generator Relay Management Pada PLTG Panaran.

7. Wisatawan, Hari dkk. Evaluasi Setting Rele Overall Differential GT 1.1 PLTGU Grati dan Rele Jarak GITET Grati pada Bus 500 kV. 